\title{
COVID-19 Pandemic and Its Impact on Pediatric Dentistry in Austria: Knowledge, Perception and Attitude Among Pediatric Dentists in a Cross-Sectional Survey
}

This article was published in the following Dove Press journal:

Journal of Multidisciplinary Healthcare

\author{
Katrin Bekes ${ }^{1}$ \\ Valentin Ritschl ${ }^{2}$ \\ Tanja Stamm ${ }^{2}$ \\ 'Department of Pediatric Dentistry, \\ University Clinic of Dentistry, Medical \\ University Vienna, Vienna, Austria; \\ ${ }^{2}$ Center for Medical Statistics, \\ Informatics, and Intelligent Systems, \\ Medical University of Vienna, Section for \\ Outcomes Research, Vienna, Austria
}

Correspondence: Katrin Bekes Department of Pediatric Dentistry, University Clinic of Dentistry, Medical University Vienna, Sensengasse 2a, Vienna 1090, Austria

Tel +43-I-40070280I

Fax +43-I-400702809

Email katrin.bekes@meduniwien.ac.at
Introduction: The Novel Coronavirus Disease (COVID-19) outbreak is affecting people worldwide. Given the frequent production of aerosols, dentists are a high-risk group for infection. The aim of this study was to assess the knowledge, perception and attitude regarding COVID-19 among pediatric dentists in Austria.

Methods: An online survey was distributed among the 128 pediatric dentists that are members of the Austrian Society of Pediatric Dentistry. The questionnaire was divided into three sections: 1) dentists' demographic characteristics, 2) general knowledge and attitude, 3) COVID-19 with a focus on pediatric dentistry.

Results: Seventy-five dentists replied; 58 questionnaires could be included in the analysis (93.1\% female). Pediatric dentists were found to have good general knowledge of COVID19. However, only $10 \%$ had attended training or lectures and $36.2 \%$ rated their role in teaching patients about COVID-19 as being very significant. At the beginning of the outbreak, $78.6 \%$ only offered emergency services. Currently, only $10.3 \%$ of the dentists work without FFP2/3 mask when producing aerosols.

Discussion: Austrian pediatric dentists were aware of the general aspects of COVID-19. Those, who had their practice open mostly followed national and international recommendations given and only offered emergency visits.

Keywords: COVID-19, pandemic, infection, pediatric dentist, infection control

\section{Introduction}

At the beginning of 2020, the World Health Organization (WHO) confirmed that a novel coronavirus caused a respiratory disease in people living in Wuhan, Hubei, China. ${ }^{1}$ First called nCoV-2019 ${ }^{2}$ and now named SARS-CoV-2, ${ }^{3}$ the virus has spread globally within a few months and has resulted in pandemic disease. ${ }^{4}$ In Austria, the first two positive cases of COVID-19 were officially detected on February 25. These were a 24-year-old man and woman, both traveling from Lombardy, Italy, to Austria. Starting on 16 March 2020, nationwide restrictive measures were ordered by the Austrian government including a curfew. Ten days later, the highest number of confirmed coronavirus infection cases within a single day was recorded during this first wave. The peak of active, confirmed cases was observed at the beginning of April in Austria. From then on, the number of confirmed coronavirus cases decreased till July. Until mid-April, public life 
continued to be severely limited by government measures. Afterwards, the first easing measures were implemented. ${ }^{5}$

Worldwide, many medical clinics including dental facilities reduced treatment of patients significantly by limiting clinical work only to non-deferrable urgent care. ${ }^{6,7}$ This was also the case in Austria during the first peak. Thereby, particularly dentists are at high risk of getting infected from patients due to the inability to maintain a safe interpersonal distance and the exposition to aerosol and droplets generated by many dental procedures. ${ }^{8}$ Particularly when patients are in the incubation period, are unaware if they are infected, or choose to conceal their infection, dental standard protective measures in daily clinical activity are not effective enough to prevent the spread of COVID-19. ${ }^{9}$

To control the infection in dental practice, guidelines were quickly published for the dental profession by the World Health Organization, Centers for Disease Control and Prevention (CDC), and the American Dental Association $(\mathrm{ADA})^{10}$ and are regularly updated since then ${ }^{11-13}$ In addition, some reports also made useful information available focusing on the signs and symptoms of COVID-19, possible ways of transmission, and referral mechanisms to increase the knowledge and prevention practices of the dental profession. ${ }^{14,15}$ Regarding Pediatric Dentistry, the American Academy of Pediatric Dentistry (AAPD) provided regular updates on their website likewise including checklists. ${ }^{16}$ Interestingly, although exceptional guidelines regarding disinfection exist and a positive attitude of dental health professionals toward disinfection regarding the COVID-19 pandemic was observed, a recent study indicated a lack of knowledge in dentists about fundamental aspects of disinfection protocols. ${ }^{17}$

Especially younger patients are an exclusive challenge to dentists. It is assumed that children exhibit only mild COVID-19 symptoms (if any), increasing the chance of being unidentified carriers. ${ }^{18}$

As COVID-19 has laid a significant burden on dentists, the aims of this study were to assess Austrian pediatric dentists' knowledge regarding the novel coronavirus, and to examine their perception of the risks associated with the disease in pediatric patients as well as their attitude to activities in dental practice. To our knowledge, this is the first study specifically addressing pediatric dentists.

\section{Materials and Methods}

\section{Study Design}

A survey of pediatric dentists in Austria was conducted. A new designed questionnaire was used to assess Austrian pediatric dentists' knowledge, perception of the risks and attitude to activities in dental practice regarding COVID-19.

\section{Setting, Participants and Sample Size}

Our study population consisted of pediatric dentists that are members of the Austrian Society for Pediatric Dentistry and work in Austria.

\section{Data Sources and Variables}

We used a self-designed questionnaire-based survey in German language in this study. The survey comprised a series of multiple-choice questions with following sections: pediatric demographic and profession-related characteristics of the dentists (6 questions), general knowledge and attitude regarding COVID-19 (9 questions), as well as attitudes and perceptions toward the disease with a special focus on pediatric dentistry (13 questions). The questions were developed after reviewing relevant literature and existing international guidelines. The first version of the questionnaire was piloted among five pediatric dentists and one statistician to ensure suitability and practicability. Based on the comments obtained by these experts, one question was added.

The survey was made available to all registered pediatric dentists in Austria via www.soscisurvey.de. The generated link was shared by the Secretary's office of the Austrian Society for Pediatric Dentistry (ÖGKiZ) via mail, inviting all members to take part in this survey. In Austria, a survey among experts is the only type of research involving humans that does not need an ethics approval. Informed consent was obtained from all participants. Only fully completed questionnaires were considered. The data obtained were absolutely anonymous, and tracing the identity of the dentists was not possible. The survey data were gathered from May 27 to June 30, 2020.

\section{Statistical Methods}

Descriptive statistics were used to summarize and analyze the data. Absolute and relative frequencies as well as measures of central tendency and dispersion were calculated as appropriate, depending on the scale level and distribution of each variable. Descriptive statistics were performed using SPSS (IBM Corp).

\section{Results}

\section{Sociodemographic Data and Profession-Related Characteristics}

From the 128 members of the Austrian Society for Pediatric Dentistry who were invited to participate, 75 
(58.6\%) replied. Participants were from all parts of Austria. Fifty-eight (45.3\%) dentists finished the questionnaire completely (Figure 1). Of these, 54 (93.1\%) were females (Table 1). More than one-third of the respondents work in Vienna, the capital of Austria. Years of dental practice ranged from 1 to 34 years with a mean of 15.6 (SD 7.7) years; mean experience in pediatric dentistry was 10.9 years (SD 6.4; range 1 to 27). Most of the study participants are working in a private practice.

\section{General Knowledge and Attitude Regarding COVID-19}

Nearly all respondents knew that the virus causing the novel coronavirus infection is called as "2019-nCoV". And, $17.2 \%$ were also aware of the name "Severe Acute Respiratory Syndrome Corona Virus - 2 (SARS CoV-2)". Almost all dentists (89.7\%) also understood that the infection can affect all age groups. In addition, more than $80 \%$ identified all correct factors currently being considered as "close contact" for the infection. Moreover, close to twothirds of the interviewees (62.1\%) properly selected all the possible ways of transmission (handshaking, coughing and sneezing, and touching surfaces) that were known at that time-point and an additional $15.5 \%$ of the participants answered only "coughing and sneezing". When asked about the incubation period, nearly $90 \%$ of the dentists correctly answered 1-14 days. Regarding the understanding of COVID-19 symptoms, one half (53.4\%) of the respondents correctly chose all the known symptoms when

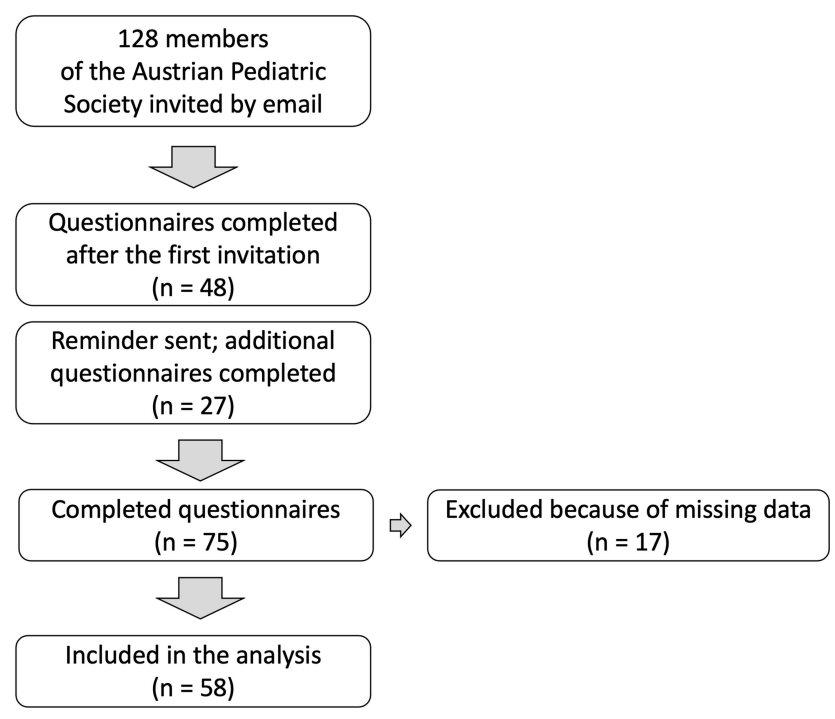

Figure I Flow chart.
Table I Demographics of the Study Participants

\begin{tabular}{|c|c|c|}
\hline Characteristics & $\mathbf{N}$ & $\%$ \\
\hline \multicolumn{3}{|l|}{ Age } \\
\hline$<30$ years & 3 & 5.2 \\
\hline $30-39$ years & 16 & 27.6 \\
\hline $40-49$ years & 20 & 34.5 \\
\hline$\geq 50$ years & 19 & 32.8 \\
\hline \multicolumn{3}{|l|}{ Gender } \\
\hline Female & 54 & 93.1 \\
\hline Male & 4 & 6.9 \\
\hline \multicolumn{3}{|l|}{ Federal States } \\
\hline Burgenland & 0 & 0 \\
\hline Carinthia & 3 & 5.2 \\
\hline Lower Austria & 6 & 10.3 \\
\hline Upper Austria & 5 & 8.6 \\
\hline Salzburg & 9 & 15.5 \\
\hline Styria & 9 & 15.5 \\
\hline Tyrol & 4 & 6.9 \\
\hline Vorarlberg & 2 & 3.4 \\
\hline Vienna & 20 & 34.5 \\
\hline \multicolumn{3}{|l|}{ Working Place } \\
\hline University & 6 & 10.3 \\
\hline University and private practice & 4 & 6.9 \\
\hline University and private practice and public health service & 1 & 1.7 \\
\hline Private practice & 39 & 67.2 \\
\hline Private practice and public health service & 4 & 6.9 \\
\hline Public health service & 4 & 6.9 \\
\hline
\end{tabular}

completing the questionnaire (Table 2). However, a high percentage $(84.5 \%)$ of the sample identified almost all symptoms (4 out of 5).

Austrian pediatric dentists mainly used Organizations of the Federal Government (86.2\%) of Austria as their source of information, followed by the Austrian Chamber of Dentists (69.0) (Table 3). In nearly half of the participants, social media played a role as well.

Austrian pediatric dentists' attitudes towards COVID19 are summarized in Table 4. More than two-thirds $(67.2 \%)$ perceived the infection in general as being moderately dangerous, one half (55.2) identified the risk of becoming personally infected as moderately dangerous. However, only one-fourth considered himself/herself in his/her personal view being prepared for the virus.

\section{COVID-I 9 and Pediatric Dentistry}

Table 5 shows different general aspects of pediatric dentistry in Austria regarding COVID-19. The participants rated the role of a pediatric dentist in teaching pediatric 
Table 2 General Knowledge Regarding COVID-19

\begin{tabular}{|l|l|l|}
\hline & N & $\%$ \\
\hline Symptoms of the COVID-19 infection & & \\
Fever & 5 I & 87.9 \\
Cough & 55 & 94.8 \\
Sore throat & 35 & 60.3 \\
Shortness of breath & 56 & 96.6 \\
Loss of smell and taste & 54 & 93.1 \\
\hline Mode of transmission & & \\
Hand shake & 42 & 72.4 \\
Coughing and sneezing & 57 & 98.3 \\
Touching surfaces such as doorknobs and tables & 42 & 72.4 \\
Correct answer of all three modes & 36 & 62.1 \\
\hline Incubation period & & \\
I-I4 days & 5 I & 87.9 \\
I-7 days & 3 & 5.2 \\
2-5 days & 4 & 6.9 \\
I-I4 hours & 0 & 0 \\
\hline
\end{tabular}

Table 3 Sources of Information

\begin{tabular}{|l|l|l|}
\hline Source of Information & N & $\%$ \\
\hline Organizations of the Federal Government & 50 & 86.2 \\
Austrian Chamber of Dentists & 40 & 69.0 \\
German Chamber of Dentists & 21 & 36.2 \\
Health professionals & 31 & 53.4 \\
Friends and family & 12 & 20.7 \\
Social media & 27 & 46.6 \\
\hline
\end{tabular}

Table 4 Attitudes Towards COVID-19

\begin{tabular}{|l|l|l|}
\hline & N & $\%$ \\
\hline How do you perceive the COVID infection in & & \\
general? & & \\
Very dangerous & 14 & 24.1 \\
Moderately dangerous & 39 & 67.2 \\
Mildly dangerous & 5 & 8.6 \\
Not dangerous & 0 & 0 \\
\hline How dangerous do you personally perceive the & & \\
risk of becoming infected? & & \\
Very dangerous & 10 & 17.2 \\
Moderately dangerous & 32 & 55.2 \\
Mildly dangerous & 13 & 22.4 \\
Not dangerous & 3 & 5.2 \\
\hline Do you consider yourself being prepared for & & \\
COVID-I 9 & & \\
Yes & 16 & 27.6 \\
No & 20 & 34.5 \\
Not sure & 22 & 37.9 \\
\hline
\end{tabular}

Table 5 COVID-19 and Pediatric Dentistry in General

\begin{tabular}{|l|l|l|}
\hline & N & $\%$ \\
\hline How important is the role of a pediatric dentist & & \\
in teaching pediatric patients and their parents/ & & \\
guardians about COVID-I9? & & \\
Very significant & 21 & 36.2 \\
Moderately significant & 21 & 36.2 \\
Mildly significant & 13 & 22.4 \\
Not significant & 3 & 5.2 \\
\hline Are you aware of the AAPD guidelines on & & \\
COVID-I9 infection control? & & \\
Yes & 13 & 22.4 \\
No & 31 & 53.4 \\
Not sure & 14 & 24.1 \\
\hline Did you attend a seminar on CoVID-19 infection & & \\
control? & & \\
Yes & 6 & 10.3 \\
No & 28 & 48.3 \\
Would like to & 24 & 41.4 \\
Not interested & 0 & 0 \\
\hline To what extent do you have confidence in & & \\
handling suspected COVID infections as & & \\
a pediatric dentist? & 18 & 31.0 \\
To a great extent & 32 & 55.2 \\
To a little extent & 8 & 13.8 \\
Not at all & & \\
\hline
\end{tabular}

patients and their parents/caregivers about COVID-19 being very significant as well as moderately significant in $36.2 \%$. Only one-fourth (22.4\%) knew about the AAPD guidelines on infection control, and only $10.3 \%$ had attended a seminar on COVID-19 infection control. However, more than $40 \%$ would like to attend one in the near future. One-third (31.0\%) had confidence in handling suspected COVID infections as a pediatric dentist.

Dental services offered by pediatric dentists in Austria at different time points of the pandemic are summarized in Table 6. During the curfew, only $72.4 \%$ of the dentists had their practices open and offered emergency treatment (78.6\%) or limited services (21.4\%) only. No dentist offered services on a regular basis to a full extend. With implementation of the first easing measures in Austria, more dentists opened again (89.7\%), mainly still offering limited services (71.2\%). In the beginning of May 2020, almost all pediatric dentists opened again (96.6\%), offering full services in more than half of the cases (58.7\%). In June 2020 , more than $80 \%$ planned to open their practices to a full extend (Table 7). 
Table 6 Dental Services Offered by Pediatric Dentists in Austria at Different Time Points of the Pandemic

\begin{tabular}{|c|c|c|c|c|c|c|}
\hline & \multicolumn{2}{|c|}{$\begin{array}{l}\text { Have You Had Your Dental } \\
\text { Practice Open During the } \\
\text { Complete Curfew in Austria } \\
\text { Starting on 16th March } 2020 \text { and } \\
\text { Ending on 13th April 2020? }\end{array}$} & \multicolumn{2}{|c|}{$\begin{array}{l}\text { Did You Open Your Dental } \\
\text { Practice with the Imple- } \\
\text { Mentation of the First Easing } \\
\text { Measures in Austria Starting } \\
\text { from 14th 2020? }\end{array}$} & \multicolumn{2}{|c|}{$\begin{array}{l}\text { To What Extent Wil } \\
\text { You Offer Dental } \\
\text { Services Beginning } \\
\text { May 2020? }\end{array}$} \\
\hline & $\mathbf{N}$ & $\%$ & $\mathbf{N}$ & $\%$ & $\mathbf{N}$ & $\%$ \\
\hline No & 16 & 27.6 & 6 & 10.3 & 2 & 3.4 \\
\hline Yes & 42 & 72.4 & 52 & 89.7 & 56 & 96.6 \\
\hline \multicolumn{7}{|l|}{ Yes } \\
\hline To full extent & 0 & 0 & 7 & 13.5 & 32 & 58.6 \\
\hline Limited & 9 & 21.4 & 37 & 71.2 & 23 & 39.7 \\
\hline Only for emergency treatment & 33 & 78.6 & 8 & 15.4 & 1 & 1.7 \\
\hline To full extent & & & 7 & 100 & 32 & 100 \\
\hline Check-up & & & 7 & 100 & 32 & 100 \\
\hline Prophylaxis & & & 4 & 57.1 & 31 & 96.7 \\
\hline Endodontics in primary teeth & & & 5 & 71.4 & 31 & 96.7 \\
\hline Caries treatment (rotating burs) & & & 7 & 100 & 32 & 100 \\
\hline Caries treatment (ART technique) & & & 7 & 100 & 25 & 78.1 \\
\hline Temporary fillings & & & 5 & 71.4 & 27 & 84.4 \\
\hline Long-term fillings & & & 7 & 100 & 32 & 100 \\
\hline Extraction & & & 7 & 100 & 32 & 100 \\
\hline Limited & 9 & 100 & 37 & 100 & 23 & 100 \\
\hline Check-up & 3 & 33.3 & 26 & 70.3 & 20 & 87.0 \\
\hline Prophylaxis & 1 & II.I & 4 & 10.8 & 17 & 73.9 \\
\hline Endodontics in primary teeth & 5 & 55.6 & 23 & 62.2 & 21 & 91.3 \\
\hline Caries treatment (rotating burs) & 4 & 44.4 & 26 & 70.3 & 22 & 95.7 \\
\hline Caries treatment (ART technique) & 4 & 44.4 & 18 & 48.6 & 16 & 69.6 \\
\hline Temporary fillings & 7 & 77.8 & 25 & 67.6 & 20 & 87.0 \\
\hline Long-term fillings & 6 & 66.7 & 28 & 75.7 & 23 & 100 \\
\hline Extraction & 9 & 100 & 35 & 94.6 & 23 & 100 \\
\hline Only for emergency treatment & 33 & 100 & 8 & 100 & 1 & 100 \\
\hline Check-up & 0 & 0 & 2 & 25.0 & 0 & 0 \\
\hline Prophylaxis & 0 & 0 & I & 12.5 & 0 & 0 \\
\hline Endodontics in primary teeth & 16 & 48.5 & 4 & 50 & 0 & 0 \\
\hline Caries treatment (rotating burs) & 15 & 45.5 & 4 & 50 & 1 & 100 \\
\hline Caries treatment (ART technique) & 14 & 42.4 & 1 & 12.5 & 0 & 0 \\
\hline Temporary fillings & 23 & 71.9 & 4 & 50 & I & 100 \\
\hline Long-term fillings & 17 & 51.5 & 3 & 37.5 & 0 & 0 \\
\hline Extraction & 32 & 97 & 7 & 87.5 & 1 & 100 \\
\hline
\end{tabular}

Protective measures and equipment used in pediatric dentistry in Austria are displayed in Table 8. Most dentists organized their dental practice by allowing the child to come with only one parent/caregiver (77.6\%) and giving appointments in large time intervals (63.8). Half of the participants got their protective measures from the pharmacy $(48.3 \%)$, and $44.8 \%$ also mentioned other sources as the Chamber of Austrian Dentists, the internet or private contacts.

The correct sequence for putting on the protective equipment was known by $51.7 \%$ of the dentists. Nearly two-thirds use an FFP3 mask when working in rotating mode $(60.3 \%)$. However, of all participants, only $6(10.3 \%)$ did not use any FFP2/3 masks. Half of 
Table 7 Opening of Paediatric Practices

\begin{tabular}{|l|l|l|}
\hline & $\mathbf{N}$ & $\%$ \\
\hline $\begin{array}{l}\text { When do you think that you will offer dental services to } \\
\text { the full extent? }\end{array}$ & & \\
June 2020 & 49 & 84.5 \\
July 2020 & 3 & 5.2 \\
August 2020 & 2 & 3.4 \\
September 2020 & 4 & 6.9 \\
\hline
\end{tabular}

the interviewees think that in 2022 it might be possible again to work without special protection (41.4\%).

\section{Discussion}

With COVID-19 being in the worldwide focus and dentists being confronted with this infection, there is a great need to evaluate on what base of knowledge and according to what attitudes and beliefs choices and management of activities in dental practice regarding COVID-19 are made by dentists. Until now, only very few studies assessing this aspect are available. ${ }^{7,14,19,20}$ To our knowledge, this is the first study to address pediatric dentists. Our survey provides an insight into different aspects shortly after the time of the outbreak in Austria.

In our study, females were predominant, which might be explained by the number of female dentists in pediatric dentistry in Austria being much higher than the number of male dentists. ${ }^{21}$ Eighty-one percent of the respondents work as private practitioners, including $13.8 \%$ that work half-time in private practice and half-time at university/or in public health services.

Regarding the general aspects about COVID-19, pediatric dentists in Austria provide good knowledge. Almost all participants knew the correct name of the virus causing the infection and also understood that the infection can affect all age groups. Close to $90 \%$ correctly reported that the estimated incubation period is $1-14$ days. $^{22}$ This is a very important point and essential to know for determining the safe period to treat patients. ${ }^{14}$ In these days, persons without symptoms can also spread the virus. ${ }^{20}$

Concerning the understanding of the symptoms that can be expected, a high percentage $(84.5 \%)$ of the interviewees also identified almost all symptoms as well as the known ways of transmission $(87.6 \%)$. This is in agreement with the few studies already published. Putrino et al reported that $87 \%$ of the Italian dentists were already well informed in February/March 2020 about the possible symptoms that appear with the disease, and in $60.9 \%$ of
Table 8 Protective Measures and Equipment in Pediatric Dentistry

\begin{tabular}{|c|c|c|}
\hline & $\mathbf{N}$ & $\%$ \\
\hline \multicolumn{3}{|l|}{$\begin{array}{l}\text { How do you organize your dental practice with pediatric } \\
\text { patients? }\end{array}$} \\
\hline Child is only allowed to come with one parent/guardian & 45 & 77.6 \\
\hline Only one patient with parent/guardian in waiting room & 23 & 39.7 \\
\hline Several patients in waiting room but adequate distance & 28 & 48.3 \\
\hline Appointments in large time intervals & 37 & 63.8 \\
\hline \multicolumn{3}{|l|}{$\begin{array}{l}\text { How did you get protective equipment (masks, } \\
\text { gowns, ...)? }\end{array}$} \\
\hline Dental depot & 18 & 31 \\
\hline Pharmacy & 26 & 44.8 \\
\hline Collegial contacts & 14 & 24.1 \\
\hline Other & 26 & 44.8 \\
\hline \multicolumn{3}{|l|}{$\begin{array}{l}\text { The sequence for putting on the protective equipment is } \\
\text { as follows }\end{array}$} \\
\hline Gloves, mask, eye protection, gown & 8 & 13.8 \\
\hline Gown, mask, eye protection, gloves & 30 & 51.7 \\
\hline Mask, gown, eye protection, gloves & 16 & 27.6 \\
\hline Eye protection, mask, gown, gloves & 4 & 6.9 \\
\hline \multicolumn{3}{|l|}{$\begin{array}{l}\text { If you have to work in rotating mode, which mouth guard } \\
\text { do you use? }\end{array}$} \\
\hline FFP3 & 35 & 60.3 \\
\hline FFP2 & 26 & 44.8 \\
\hline Normal mouth and nose protection & 10 & 17.2 \\
\hline Shield & 28 & 48.2 \\
\hline Normal mouth and nose protection + Shield & 9 & 15.5 \\
\hline \multicolumn{3}{|l|}{$\begin{array}{l}\text { When do you think you can work again without special } \\
\text { protection? }\end{array}$} \\
\hline 2020 (this year) & 12 & 20.7 \\
\hline 2021 & II & 19 \\
\hline 2022 & 24 & 41.4 \\
\hline 2023 & 4 & 6.9 \\
\hline Never again & 6 & 10.3 \\
\hline
\end{tabular}

the cases, they correctly answered how the new coronavirus is transmitted between persons. ${ }^{20}$ These data were supported by De Stefani et al interviewing dentists in Italy in April 2020. ${ }^{7}$ Jordanian dentists were also informed correctly on the mode of transmission and only partly missed COVID-19 symptoms. ${ }^{14}$

In Austria, most pediatric dentists obtained scientific information about the coronavirus through Organizations of the Federal Government followed by the Chamber of Dentists, health professionals and social media. This is in agreement with data obtained from other studies in Europe. Most of the Italian dentists also stated that they got information through Italian institutions as well as television, newspapers and social media or professional associations. $^{20}$ In Turkey, the websites of official entities 
such as the Ministry of Health, WHO, and professional organizations, and/or their social media accounts were primarily used. ${ }^{19}$

In our study, $24.1 \%$ of the Austrian pediatric dentists perceived the infection in general as being very dangerous, $67.2 \%$ as being moderately dangerous, respectively. Moreover, 55.2\% identified the risk of becoming personally infected as moderately dangerous. Khader et al observed similar results: most of their interviewees $(71.7 \%)$ in Jordan also rated the infection being moderately dangerous.

Our data also showed that only $27.6 \%$ of our participants considered themselves being prepared for the virus. Due to the fact that only $10.3 \%$ stated of having already attended informational meetings on COVID-19 infection control, this result may not surprise too much. However, $41.4 \%$ answered that they would like to attend such a meeting. Other countries have observed similar results. In Turkey, Duruk et al found that only one-fourth of the interviewed dentists had already attended such a meeting at the time of the survey. The authors requested that the number of such meetings should be increased, and participation in meetings should be mandatory for dentists. ${ }^{19}$ In Italy, Putrino et al also observed only a small number of dentists having visited courses on this topic. ${ }^{20}$ However, both studies were carried out much earlier during the outbreak compared to our study. A later survey in Italy showed in fact that the majority of respondents declared having been trained in procedures for prevention the infection $(64.3 \%))^{7}$

In line with these findings, only one-third felt of the Austrian pediatric dentists felt confident to a great extent in handling suspected COVID-19 infections. About half of the pediatric dentists claimed to have only little confidence. On the one hand, this might be explained with the already mentioned lack of attending trainings or informational meetings; on the other hand, the high prevalence of participants in this study being private practitioners might also justify this finding. Having universities nearby, a lot of these patients were sent to these institutions in Austria.

In terms of dental services offered by pediatric dentists in Austria, a change could be observed at different time points of the pandemic. During the curfew, marking the beginning of the pandemic in Austria, only $72.4 \%$ of the dentists had their practices open, just offering emergency treatment $(78.6 \%)$ or limited services $(21.4 \%)$. With implementation of the first easing measures in Austria, $89.7 \%$ of the pediatric dentists opened again, however, mainly still offering limited services (71.2\%). Beginning of May 2020, almost all pediatric dentists opened again, offering full services in $58.7 \%$. To our knowledge, this is the first study to collect data in this regard. However, the findings reflect recommendations given for health-care professionals in Austria. ${ }^{23}$ In accordance with other countries and international recommendations given, ${ }^{6,19,24}$ it was suggested to suspend all general non-emergency treatments and postpone elective dental procedures at the beginning of the pandemic, and to provide dental treatment only for urgent or emergency cases with preprocedural decontamination of the oral cavity using mouthwashes. $^{25}$ In China, where it all started, Guo et al reported that $94.6 \%$ of the dental visits during the first wave of COVID-19 pandemic were emergency treatment related. ${ }^{24}$

In the literature, it has been shown that many dental processes have the potential to spread bacteria and viruses to the dentist himself, the dental staff and other people in dental clinics. ${ }^{26}$

Regarding the use of personal protection, only one half of our respondents (51.7\%) knew the current state-of-theart order for putting on protective equipment, which is gown, mask, eye protection (where required) and gloves. The majority $(60.3 \%)$ of the pediatric dentists use a FFP3 mask when aerosols are produced (eg drilling), probably thinking that a surgical mask does not protect to prevent cross-infection of COVID-19. Ahmed et $\mathrm{al}^{27}$ interviewed 669 participants from 30 different countries worldwide regarding this topic. Interestingly, they observed that on the one hand, $85 \%$ of the dentists believed that a surgical mask is not adequate for prevention, but on the other hand, $84 \%$ favored their use for routine dental procedures and moreover, 90\% reported not using an N-95 mask during patient treatment. This is an interesting finding, as it is known that airborne transmission through aerosols produced in medical procedures is another probable route of transmission of COVID- $19^{28}$ and may leave dentists in potentially high-risk situations.

\section{Strengths and Limitations}

This study has a range of strengths and limitations. As a strength, a nationwide design was chosen. However, Austria is a small country and the Society of Pediatric Dentistry has only 128 members that practice dentistry in Austria. The response rate was only $45.3 \%$. This resulted in a smaller than expected sample size. However, we did not perform a non-responder analysis, since it was not 
possible in the present study due to the anonymous response. Moreover, we might not have reached other eligible pediatric dentists, eg pediatric dentist who practice in Austria, but are not members of the Austrian Society. However, it can be assumed that with we were able to reach the majority of pediatric dentists in Austria. Furthermore, the members of the Austria Society for Pediatric Dentistry are mostly colleagues with strong involvement in the discipline. We have pre-tested the questionnaire to five dentists. This could have introduced a bias in terms of validity and reliability. As for all surveys, another limitation is that data were collected in a concise duration of time. COVID-19 outbreak had a rapid effect on the practices of dentists. It may be discussed that the knowledge and attitudes of pediatric dentists may alter with the emerging research of the virus causing the infection.

\section{Conclusions}

Based on a nationwide sample of members of the Austrian Society of Pediatric Dentistry, pediatric dentists had a substantial knowledge and were aware of symptoms, mode of transmission, and infection control regarding COVID-19. During the curfew, most dentists followed the recommendations to provide emergency or limited services. Nevertheless, further studies with a much larger sample size and longer follow-up period are needed to achieve more precise results regarding the long-term implications of COVID-19 on pediatric dentists.

\section{Ethical Approval}

In Austria, a survey among experts is the only type of research involving humans that does not need an ethics approval. The internal data protection committee of the Medical University of Vienna is only responsible for surveys among employees of the university. As our participants were from all parts of Austria, no approval was needed.

\section{Funding}

No funding was received.

\section{Disclosure}

Prof. Dr Tanja Stamm reports personal fees from Sanofi, AbbVie, and Roche, outside the submitted work. The authors declare that they have no other conflicts of interest in this work.

\section{References}

1. World Health Organization (WHO). Novel coronavirus (2019-nCoV). Situation report-1; 2020. Available from: https://www.who.int/docs/ default-source/coronaviruse/situation-reports/20200121-sitrep -1-2019-ncov.pdf. Accessed July 22, 2020.

2. Chen L, Liu W, Zhang Q, et al. RNA based mNGS approach identifies a novel human coronavirus from two individual pneumonia cases in 2019 Wuhan outbreak. Emerg Microbes Infect. 2020;9:313-319. doi:10.1080/ 22221751.2020.1725399

3. Cui J, Li F, Shi ZL. Origin and evolution of pathogenic coronaviruses. Nat Rev Microbiol. 2019;17:181-192. doi:10.1038/s41579-018-0118-9

4. World Health Organization (WHO). Rolling updates on coronavirus disease (COVID-10); 2020. Available from: https://www.who.int/ emergencies/diseases/novel-coronavirus-2019/events-as-they-happen. Accessed July 22, 2020.

5. Pollak M, Kowarz N, Partheymüller J. Chronology of the corona crisis in Austria - Part 1: background, the way to the lockdown, the acute phase and economic consequences; 2020. Accessed August 11, 2020.

6. Amato A, Caggiano M, Amato M, Moccia G, Capunzo M, De Caro F. Infection control in dental practice during the COVID-19 pandemic. Int $J$ Environ Res Public Health. 2020;17:4769. doi:10.3390/ijerph17134769

7. De Stefani A, Bruno G, Mutinelli S, Gracco A. COVID-19 outbreak perception in Italian dentists. Int J Environ Res Public Health. 2020;17:3867. doi:10.3390/ijerph17113867

8. Spagnuolo G, De Vito D, Rengo S, Tatullo M. COVID-19 outbreak: an overview on dentistry. Int $J$ Environ Res Public Health. 2020;17:2094. doi:10.3390/ijerph17062094

9. Meng L, Hua F, Bian Z. Coronavirus disease 2019 (COVID-19): emerging and future challenges for dental and oral medicine. $J$ Dent Res. 2020;99:481-487. doi:10.1177/0022034520914246

10. World Health Organization (WHO). Clinical management of severe acute respiratory infection (SARI) when COVID-19 disease is suspected: interim guidance. World Health Organization. License: CC BY-NC-SA 3.0 IGO; 2020. Available from: https://apps.who.int/iris/ handle/10665/331446. Accessed August 11, 2020.

11. World Health Organization (WHO). Clinical management of COVID-19; 2020. Available from: https://www.who.int/publications/ i/item/clinical-management-of-covid-19. Accessed August 11, 2020.

12. Centers for Disease Control and Prevention (CDE). CDC releases interim reopening guidance for dental settings; 2020. Available from: https://www.cdc.gov/oralhealth/infectioncontrol/statement-COVID. html. Accessed August 25, 2020.

13. American Dental association (ADA). CDC guidance for dental settings echoes ADA guidance; 2020. Available from: https://www.ada. org/en/press-room/news-releases/2020-archives/may/cdc-guidancefor-dental-settings-echoes-ada-guidance?utm_source $=$ cpsorg\&utm medium $=$ cpsalertbar\&utm_content $=$ ada-

cdcstatement\&utm_campaign=covid19. Accessed August 25, 2020.

14. Khader Y, Al Nsour M, Al-Batayneh OB, et al. Dentists' awareness, perception, and attitude regarding COVID-19 and infection control: cross-sectional study among Jordanian dentists. JMIR Public Health Surveill. 2020;6:e18798. doi:10.2196/18798

15. Azim AA, Shabbir J, Khurshid Z, Zafar MS, Ghabbani HM, Dummer PMH. Clinical endodontic management during the COVID-19 pandemic: a literature review and clinical recommendations. Int Endod J. 2020;53(11):1461-1471. doi:10.1111/iej.13406

16. American Association of Pediatric Dentistry (AAPD). Re-emergence pediatric dentistry. Practice Checklist; 2020. Accessed August 11, 2020.

17. Sarfaraz S, Shabbir J, Mudasser MA, et al. Knowledge and attitude of dental practitioners related to disinfection during the COVID-19 pandemic. Healthcare (Basel). 2020;8. doi:10.3390/healthcare 8030232 . 
18. Ludvigsson JF. Systematic review of COVID-19 in children shows milder cases and a better prognosis than adults. Acta Paediatr. 2020;109:1088-1095. doi:10.1111/apa.15270

19. Duruk G, Gumusboga ZS, Colak C. Investigation of Turkish dentists' clinical attitudes and behaviors towards the COVID-19 pandemic: a survey study. Braz Oral Res. 2020;34:e054. doi:10.1590/18073107bor-2020.vol34.0054

20. Putrino A, Raso M, Magazzino C, Galluccio G. Coronavirus (COVID-19) in Italy: knowledge, management of patients and clinical experience of Italian dentists during the spread of contagion. BMC Oral Health. 2020;20:200. doi:10.1186/s12903-020-01187-3

21. Austrian Society of Pediatric Dentistry (ÖGKiZ): ÖGKiZ member database; 2020. Available from: https://www.kinderzahnmedizin.at/ index.php/de/ordinationen/language-style2/mitgliederliste. Accessed September 13, 2020.

22. Li Q, Guan X, Wu P, et al. Early transmission dynamics in Wuhan, China, of novel coronavirus-infected pneumonia. $N$ Engl J Med. 2020;382:1199-1207. doi:10.1056/NEJMoa2001316

23. Gesundheit Österreich $\mathrm{GmbH}$ (GÖG). Handlungsempfehlung fur selbstandig tatige Gesundheitsberufe 16. 03.2020; 2020. Available from: https://www.zahnaerztekammer.at/fileadmin/content/oezak/ Corona-Handlungsempfehlung_BMG.pdf. Accessed August 24, 2020 .
24. Guo H, Zhou Y, Liu X, Tan J. The impact of the COVID-19 epidemic on the utilization of emergency dental services. J Dent Sci. 2020;15 (4):564-567. doi:10.1016/j.jds.2020.02.002

25. Imran E, Khurshid Z, Tariq K. Preprocedural use of povidone-iodine mouthwash during dental procedures in the COVID-19 pandemic. Eur J Dent. 2020. doi:10.1055/s-0040-1717001

26. Harrel SK, Molinari J. Aerosols and splatter in dentistry: a brief review of the literature and infection control implications. $J \mathrm{Am}$ Dent Assoc. 2004;135:429-437. doi:10.14219/jada. archive.2004.0207

27. Ahmed MA, Jouhar R, Ahmed N, et al. Fear and practice modifications among dentists to combat novel coronavirus disease (COVID-19) outbreak. Int $J$ Environ Res Public Health. 2020;17:2821. doi:10.3390/ijerph17082821

28. Wax RS, Christian MD. Practical recommendations for critical care and anesthesiology teams caring for novel coronavirus (2019-nCoV) patients. Can J Anaesth. 2020;67:568-576. doi:10.1007/s12630-02001591-x
Journal of Multidisciplinary Healthcare

\section{Publish your work in this journal}

The Journal of Multidisciplinary Healthcare is an international, peerreviewed open-access journal that aims to represent and publish research in healthcare areas delivered by practitioners of different disciplines. This includes studies and reviews conducted by multidisciplinary teams as well as research which evaluates the results or conduct of such teams or healthcare processes in general. The journal covers a very wide range of areas and welcomes submissions from practitioners at all levels, from all over the world. The manuscript management system is completely online and includes a very quick and fair peer-review system. Visit http://www.dovepress.com/testimonials. php to read real quotes from published authors. 